\title{
Towards Interdisciplinarity in the Arab World: The Need for Interdisciplinary Studies in the Nascent Saudi Universities
}

\author{
Abdelmagid Abdelrahman Awadelkarim ${ }^{1}$
}

\begin{abstract}
${ }^{1}$ Department of English, College of Education, Majmaah University, Majmaah, Saudi Arabia Correspondence: Abdelmagid Abdelrahman Awadelkarim, Majmaah University, Saudi Arabia. Email: abdelmagid777@yahoo.com
\end{abstract}

Received: January 17, 2019 Accepted: February 14, $2019 \quad$ Online Published: March 1, 2019

doi: 10.23918/ijsses.v5i3p95

\begin{abstract}
Interdisciplinary studies/sciences are currently flourishing in numberless Western universities. There are currently, a variety of interdisciplinary research centres, programmes and departments, in many Western universities (sometimes even colleges as in the case of University of British Columbia in Canada). International conferences and special magazines are presently being dedicated to these issues and trends all over the world. By way of contrast, the Arab world, with the exception of very few cases, this tendency is yet to be known, let alone be introduced. It would, therefore, be immensely imperative for the nascent universities, Majmaah university included, to introduce interdisciplinary studies in their undergraduate/postgraduate programmes/plans. It is here that the nascent universities in the Arab world can markedly excel by exploring new horizons, as well as by probing a largely virgin space in education and research. In this way, they can get more competitive in an increasingly tough and pressing labour market, hence can considerably contribute to the knowledge economy of today's time.

This paper argues for the need to incorporate interdisciplinary studies/sciences and interdisciplinarity, into the programmes of Arab universities, in general, and the newly established Saudi ones, to be more specific (Majmaah). Data were collected via an array of mixed methods. Chiefly, group discussions and interviews with top managers, high-ranking administrators, educationalists, scholars and pundits from all walks of academia were exploited in the study. Analysis primarily drew on an integration of both qualitative and quantative methods (noting that much of the data required in this study is of qualitative nature, and that much more recent social/human sciences research has importantly disclosed a special inclination towards qualitative data gathering and analysis). Results largely suggest not only the need for adopting and introducing interdisciplinary studies and interdisciplinarity in Majma'ah university, but also, generalizably in the rest of the other newly-established universities/colleges and Arab academia, at large.
\end{abstract}

Keywords: Interdisciplinary Studies/Research, New Research Perspectives, Multidisciplinarity, TransDisciplinarity, Cross-Disciplinarity, Intra-Disciplinarity, Pluri-Disciplinarity, Post-Disciplinarity, Arabic Universities, Nascent Universities

\section{Introduction}

Excessive or overspecialization has been a landmark characteristic of modern education, particularly since the late $19^{\text {th }}$ and early $20^{\text {th }}$ centuries. 'Disciplinarity' is predominantly a product of the twentieth century. Particularly since the outset of the $21^{\text {st }}$ century, "the disciplinary subjects" (or what is known as the "disciplinary big bang") has increasingly been attacked for its many shortcomings and limitations, and the disciplines started to be seen as out of their depth in attempting to incorporate the complexity and 
inclusiveness of contemporary human knowledge, which is "without precedent in human history", to borrow Nicolescu's phrase (2002, p. 6). Resultantly, "interdisciplinarity" and interdisciplinary studies, have been introduced in countless Western universities for the sake of accommodating the huge developments inside, between, across and beyond the traditional disciplines (Klein, 1990, 2002, 2005, 2010; Nicolescu, 2002; Hutcheon, 2004; Norgaard, 2005).

Interdisciplinarity has brought the seemingly isolated islands (natural sciences and the humanities/social sciences) once again closer together. Other chief driving forces for interdisciplnarity are globalization, cyberisation and the ideas of postmodernity. Interdisciplinary studies/sciences have a wide range of effects and implications (a myriad of interdisciplinary fields include: nanotechnology, eco-science, eco-criticism, meta-criticism biometrics, cybernetics, biolinguistics, ergonomics, cognitive science, bioinformatics, biotechnology, bioelectronics, culture studies, women's studies, discourse analysis, quantum physics, memetics, semiosis, applied ethics), to mention but a few, though there is much more to interdisciplinarity than just the merging of disciplines (Hutcheon, 1997). Meanwhile, many fields have been redefined as "interdisciplinary", with a growing inclination in research to mix data collection techniques and analysis, and to draw on a multitude of integrated qualitative and quantative methods (e.g. prospective, introspective and retrospective data), ( Axinn \& Pearce, 2007).

This study discusses the need for introducing interdisciplinarity and interdisciplinary studies in the academic and training programmes of the nascent Saudi universities and colleges. The history and growth of modern "disciplinarity" is probed, leading to the rise of interdisciplinarity. Afterwards, key theories, concepts, functions and characteristics of "interdisciplinarity" are scrutinized and the driving forces (e.g. digitalization and postmodernism) that have given rise to the movement of "interdisciplinarity" are debated and explored. Next, the treatment examines the overlap and interrelationships between the term interdisciplinarity and a host of other related terms: intra-disciplinarity, cross-disciplinarity, multidisciplinarity, pluridisciplinarity, transdisciplinarity and post-disciplinarity.

The philosophy / rationale for interdiscipliarity is then debatingly demonstrated, with particular emphasis laid on Kuhn's theories of "incommensurablity" and' paradigm shift" (these two are importantly presented in the study as a conceptual framework for interdisciplinary studies/interdisciplinarity).

The various problems, drawbacks, limitation and challenges of interdisciplinary studies are also laid bare, with opposing arguments occasionally juxtaposed. Most importantly, the need for introducing interdisciplinary studies/interdisciplinarity, in Arabic/Saudi academia, in general, and the Saudi nascent universities/colleges, including Majma'ah, in particular, is strongly argued for. It is shown that the Arab universities are, to a large extent, long lagging behind the world universities in this respect, and that the nascent universities can especially excel by introducing interdisciplinarity in their under/postgraduate study plans. Ultimately, the implications for interdisciplinary studies for knowledge economy and labour market are crucially displayed and discussed, and it is concluded that interdisciplinarity can particularly improve the graduates' competitiveness in today's sweepingly changing economy and greatly challenging labour market. One way of making graduates more competitive in the market, is via seeking to cater for a range of "interdependent skills", highly required by many employers, and which only interdisciplinary studies can tremendously offer. 


\subsection{Questions}

The study seeks to primarily answer questions about the need for interdisciplinarity and interdisciplinary studies in the Saudi nascent universities, which are also considered applicable, in many ways, to Arabic academia in general terms.

In general, the study seeks to tackle and find answers the following questions:

1. How important and useful is Interdiscipliarity for today's research philosophy?

2. How important and useful are Interdisciplinary Studies for today's higher education?

3. What are the possible benefits from introducing interdisciplinarity and interdisciplinary studies in Arabic universities and the academia of the Arab world?

4. What are the ways in which the introduction of interdisciplinarity and interdisciplinary studies can be said to benefit the nascent Saudi universities, in particular?

\subsection{Hypotheses}

The study is principally of exploratory nature (exploratory studies do not draw much on hypotheses, but tend to probe the issue and explore the problem from various perspectives seeking to unveil new facts or highlight new questions about a problem). This study, although being exploratory in nature, and purports chiefly to foreground questions of interdisciplinarity and interdisciplinary studies(stated above) in the Arab world, in general, and the Saudi (nascent universities), in particular, is nevertheless, also built on the following hypotheses:

\section{H.1}

Interdisciplinarity and Interdisciplinary Studies are unknown/unrecognized in most of the Arab universities.

\section{H.2}

Introducing or adopting Interdisciplinarity and Interdisciplinary Studies will benefit the nascent university of Majmaah.

\section{Theory and Literature}

\subsection{The Disciplining of Knowledge and the Development of Disciplinarity}

The problem of the division of knowledge and "disciplinarity" lies deeply buried in the problem of modern education itself. The question of the history of the beginning of the disciplines is somewhat debatable. Some sources like Moran (2002), trace the beginning as far back as the Greek times. In what appears to be a drawing on the ideas of power relations analysis and epistemological digging, which in turn lie deeply anchored in the methodology of critical discourse analysis, Moran notes that the word discipline has two meanings: the sense of controlling and punishing (hence, the word "disciple which means "student") and (the idea of a branch of knowledge studied independently). The two senses of the term "discipline" indicates there is a power element underscoring its current use (also hinted by Foucault's, 1995 concept of "institutional discipline"). 
However, the bulk of the literature, epitomized by Klein (1990, 2002, 2005, 2010), anticipates that "disciplinarity" is largely a product of modern time education, particularly flourishing during the twentieth century, culminating in what is later dubbed as "the disciplinary big bang". The latter stance looks more accurate, since the disciplines in the rigid sense of today did not exist in classical times, be it the in its Greek and Roman manifestation (e.g. Platonic Academy founded in Athens, 387 B.C.) or in its Arabic realization (House of Wisdom, established during the Abbasid reign by Caliph al-Rashid and his son alMamun). Classical scholars, though cannot exactly be labeled "interdisciplinary", in the real since of today's' "interdisciplinarity", were, nonetheless, much more aware of the unity of knowledge, and would often take a broader perspective for whatever topic they were investigating.

Another important factor behind the development of "disciplinarity" was the rationalistic and enlightenment philosophers whose perspectives had shaped all aspects of European modernity, fleshing out in education more than anywhere else. The age of reason, was considerably stamped by the "mindbody" duality initiated by Descartes in the seventeenth century. Significantly, this "duality" has since, to a large extent, branded both educational philosophy and practices, resulting in the separation of knowledge that we see today. It is only recently that this" duality" has been rejected and a holistic approach overpasses the traditional" subject-object" separation. Drawing on Heidegger (1996), Lise (2004, p.3) holds that "Descartes saw these two things as completely separate orders of being, which do not fundamentally interact but "merely operate in parallel". The Cartesian tradition provides two options for theorists: to take either an objective or a subjective stance. However, both stances entail problems". Heidegger's call for subject-object integration (also advocated by Kierkegaard, Husserl and their transcendentalist predecessors), has ultimately materialized in the "phenomenological methods" in research and in the bundle of other methods seeking to blend qualitative and quantitate data collection and analysis techniques.

The industrial revolution that swept the West during the nineteenth century and early twentieth century, beginning first in England and then crossing the Atlantic to the United States, was undoubtedly a breaking event that was both a product and a reason of the rise of "disciplinarity", which would eventually brand the totality of world education. As knowledge expanded unprecedentedly, due to a multitude of factors, the traditional disciplines were beginning to shrink, paving the way for interdisciplinary studies, and consequently, the rise of interdisciplinarity to fill the many gaps, drawbacks and limitations of disciplinarity. This process, started presumably during the sixties and seventies of the twentieth century, but has been particularly enhanced over the last decade of this century.

\subsection{The Rise of Interdisciplinarity and the Spread of Interdisciplinary Studies}

The gap left by disciplinarity and the traditional disciplinary subjects inept to accommodate the unprecedentedly huge expansion of present-day knowledge (Klein, 1990, 2002, 2005, 2010; Nicolescu, 2002; Hutcheon, 2004; Norgaard, 2005), and has brought about the present range of perspectives and practices of interdisciplinarity. This section will discuss key concepts, definition, philosophy and problems of interdisciplinary studies/interdisciplinarity. Meanwhile, the various overlaps, interrelationships and differences between the term "interdisciplinarity" and a variety of other related terms will be delineated: intra-disciplinarity/crossdisciplinarity/multidisciplinarity, transdisciplinarity and post-disciplinarity. 


\subsection{Definitions and Key Concepts of Interdisciplinarity}

The literature is awash with various disagreements over the exact definition of "interdisciplinarity/disciplinary studies" on the one hand, and the ways in which it can be distinguished from the load of other pertaining terms, on the other: intradisciplinarity/crossdisciplinarity/multidisciplinarity, transdisciplinarity and post-disciplinarity. This treatment will take a rather tolerant stance to the differences, for the following reasons:

1. Despite the differences between scholars as to which is better and larger in meaning and approach, the meeting point of all (intra-disciplinarity exempted), is the dissatisfaction of the domain and methods of the traditional disciplinary subjects.

2. It suffices for the purposes of this study to attempt to unearth the crying need to introduce the concept of "interdisciplinarity", broadly defined, in the context of Arab/Saudi universities, in general, and the nascent Saudi universities/colleges, in more specific terms.

3. In Western universities, the departments/centres/colleges dealing with these studies are more commonly to be called "interdisciplinary", than by any of the remainder of the terms.

Although the disagreements respecting the meaning of these terms, will be skipped for the reasons stated above, a glimpse, at these differences will, herein, still be deemed useful:

1. Intra-disciplinarity, is concerned about the interaction between the various scholars within the same discipline. As many scholars note, the gap seems widening, as a direct pitfall of the "disciplinary big bang", between those who work within the boundary of the same discipline, (cf. section 4.1).

2. The key feature of "interdisciplinarity" is that of "interaction" between two or a range of disciplines or between scores of scholars from various specialty backgrounds, and that this interplay actually plays a crucial role in solving many problem. Whilst some scholars, see the term "interdisciplinary" as almost entirely synonymous with "transdisciplinary", some others like Nicholesu (2002) insist that the purpose of "transdisciplinarity" is "the understanding of the present world, of which one of the imperatives is the unity of knowledge" (p. 4).

3. In spite of his emphasis on the "complementary character' of disciplinarity, multidsciplinarity, pluridisciplinarity, interdisciplinarity and transdisciplinarity, Nicholescu (p. 6) argues that the problem with these , transdisciplinarity precluded, though all cross disciplinary borders, still stay within the general "framework of disciplinary boundaries" (p. 3). He defines pluridiscipnarity as "studying a research problem not in only one discipline, but in several at the same time" (p. 3); multidisciplinarity as an area that "overflows disciplinary boundaries" (p. 3), and interdiscipluinarity as characterized by "the transfer of methods from one discipline to another" (p.4). Probably contrarily to this, Hutcheon (1997, p. 4) believes that interdisciplinarity "necessarily means more than merely encouraging individual students or professors to select whatever they choose to study from among an aggregate of unconnected opinions across a number of subject boundaries. Surely, it must involve the building of authentically scientific studies". Emphasising the imperative function of interdisciplinarity in borrowing and sharing methods among disciplines, Dale (2008), refers to two methods: Optimal Matching Analysis, (which the social sciences borrowed from DNA sequencing) and Social Network Analysis (shared by a 
variety of disciplines). Dale's view of interdisciplinarity like Klein's (1990, 2002, 2005, 2010), appears much broader than merely the borrowing of methods, including epistemological and psychological aspects.

4. Reviewing (INTERDISCIPLINARITY: Problems of Teaching and Research in Universities (Paris: OECD,1972)), which includes the results of the first international conference on "interdisciplinarity", Klein (1990, pp. 38-39 ), sums up the term definitions as: "multidisciplinary" as juxtaposition of disciplines that are not necessarily connected; and "pluridisciplinary" as juxtaposition of disciplines assumed to be more or less related; "interdisciplinary" as interactions between more than one discipline, and "transdisciplinary" as system of axioms.

5. Post-disciplinarity, like post-method in applied linguistics, tends to take a critical approach to the inherent limitations/shortcomings of the idea of "disciplinarity" itself, and seeks to liberate knowledge from the confinements of all disciplines.

6. The following diagram is proposed by Jensenius (2012 originally based on Zeiger,1990), in an attempt to represent the meanings of these contentious terms: Intra-disciplinarity, Multidisciplinarity, Cross-disciplinarity, Interdisciplinarity and Trans-disciplinarity:
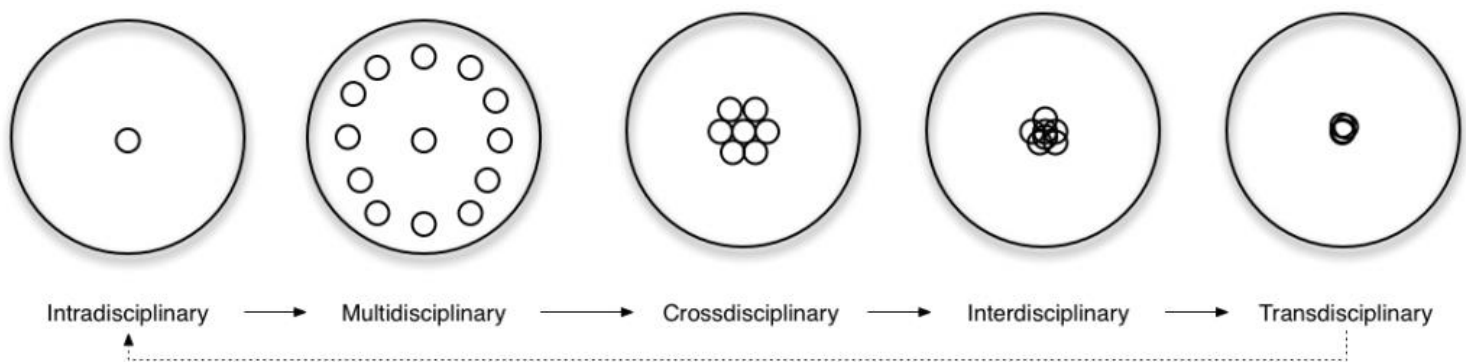

Figure 1: The meanings of the terms (source: Jensenius, 2012, http://www.arj.no).

\subsection{Philosophy and Rationale for Interdisciplinarity}

The following arguments, would presumably epitomise the overall rationale and philosophy, that are usually used in the literature for adopting interdisciplinary studies and interdisciplinarity:

1. Working across traditional disciplinary boundaries provides an opportunity for a more profound perspective into a particular problem. Seeing the research problem from multiple angles, which will more likely produce a deeper understanding, will also be more likely to result into a better solution of that problem.

2. Scholars and students working between, across or beyond the disciplines will more probably get their perspective/approaches and expertise broadened and enriched (Dale, 2008). This is similar to what Hutcheon (1997), calls, the importance of establishing a " common language community", among scholars.

3. Interdisciplinary studies and research provides a sort of epistemological restructuring and reshaping of education. 
4. Bridging the gap between the traditional classifications of the sciences into: natural and human/social. Unity of knowledge would appear to have been the key principle of education/scholarship for a long time during the classical and middle ages, before it was abrogated by the current taxonomies of modern education (Moran, 2002). The 'disciplining' of knowledge, as mentioned earlier in this study, is to a large extent, the work of the late $19^{\text {th }}$ and early $20^{\text {th }}$ centuries (Lattuca, 2001). This fact, has prompted many scholars to trace 'interdisciplinarity' back to the time of the Greeks and Romans. However, some others argue that the classical and mediaeval "mishmash" practices, cannot be called 'interdisciplinarity', since the disciplines as we know them today, did not exist, and that this period can be called the "pre-disciplinary era" (cf. section 2).

5. It has also been pointed out that, as a result of technology and the increasing digitalization process, new areas of study, that are so complex for any one discipline to satisfactorily deal with, have emerged. These include the study of the social impact of computer and technology, nanotechnology, eco-science, eco-criticism, biometrics, cybernetics biolinguistics, ergonomics, cognitive science, bioinformatics, biotechnology, bioelectronics culture studies, women's studies, discourse analysis, quantum physics, memetics, semiosis, applied ethics, etc. It is in the very nature of these fields to go beyond traditional discipline limits requiring a much wider outlook such as the one provided by interdisciplinarity (see sections $3.1 \& 3.2$ ).

6. The influence of globalization and postmodernity has been so colossal that it has resulted in anticentrism culture, including what might be labeled an "anti-discipline-centric" attitude. Hutcheon (2004, p. 1) notes that "the study of the humanities, can no longer divide itself into philosophy, literature, history, and social theory, expecting all the while to maintain intellectual and disciplinary autonomy". Conjointly, globalisation has reshaped the world by opening doors of all kinds, and postmodernity/postmodernism has encouraged the critical re-questioning and reinvestigating of everything including what postmodernist have pejoratively labeled as "grand narratives" (big schools of thought that have dominated the world educational and philosophical scene for ages). Since the early sixties, continental philosophers/postmodernist scholars, have all launched massive attacks on the tenets of modernism, including its, underlying ideologies, taxononmies, "specialisation" and ego-centric pillars. !!

7. Research has unveiled that working across disciplines is more likely to clear away many of the misconceptions and stereotypes that one usually holds about other disciplines, hence helps researchers broaden the ways of their thinking, become more innovative and gain more friends (Klein, 2002; Dale, 2008).

8. Another active force, in bringing about interdisciplinarity, has been the development of intradisciplinary studies and research. The disciplines that have grown weightier and fatter since the start of the twentieth century, have broadened from within, so much that each one has seen the necessity to interact within its own various branches (e.g. the development of holistic medicine and informedical communications). Pointing to the differences that may arise within the same discipline, Lattuca (2001, p. 3) maintains that "it is no longer safe to assume that faculty within particular disciplines, share the same interest, methods, or even epistemological perspective". The discoveries of the benefits of internal interaction (intra-disciplinary), have encouraged seeing the importance of interaction between the disciplines; thence, the birth of (interdisciplinary). The integration of the seemingly distinct disciplines, can even "directs our attention to aspects of disciplines and disciplinary knowledge that often remain hidden... disciplinary integration forces 
us to consider the assumptions and conventions that define particular disciplines, and that make them similar or different from others" (Lattuca, 2001, p. 23). Correspondingly, Nicolescu (n.d.) insightfully notes that nowadays "two specialists in the same discipline must make a serious effort in order to understand their respective results".

Concurrently, postmodernists such as Heidegger (1996), Foucault (1994, 2002, 2006), Derrida (1973, 1976, 1987), Fairclough (1989) etc., were fathoming the depths and breadths of the relationship between the 'self' and the 'other', the 'subjective' and the 'objective', power and language, and the debates of the 'scientific' and 'unscientific'.

\subsection{Theoretical Frame: Interdisciplinarity and Thomas Kuhn's Theories of "Paradigm Shift" and "Incommensurability"}

Since its first publication in 1962, Kuhn's "The Structure of Scientific Revolutions", has been incredibly influential in laying down the foundation of a sound theory of the development of science and the life cycle of a discipline. Chiefly, Kuhn introduced the theory of "Paradigm Shift" and the concept of "Incommensurability". In 'paradigm shift", Kuhn breaks away with the dominant interpretation of the development of disciplines which draws on the notions of "continuity" and "accumulation" and suggests that at a certain stage, the dominant paradigm (interpretative framework among the academic community within the discipline) becomes overwhelmed by new data and facts to the point of being no longer inefficient. In consequence, a totally new system of interpretation takes over, and then a "paradigm shift" occurs (disciplines pass through "pre-paradigm" in which there is no widely accepted frame of reference, "paradigm" in which there exists a widely agreed upon frame of reference and then a "paradigm shift" when a new frame of reference takes place). If the analogy is not pushed too far, this is similar to the biological concept of "mutation".

On the other hand, "incommensurability", is the belief that the differences between the various competing paradigms within a particular field of study, are, to a large extent, the product of completely different perspectives or world views that lack a common ground or standard of measurement upon which they could be validly judged (they are incommensurable). Incommensurability has been referred to, by various scholars with more or less slight differences. Notably, the theory has been advocated by Feyerabend, (1962) and Einstein, (1949). Thus, Oberheim and Hoyningen-Huene, (2012, p. 21) sum up the marrow of the theory that was introduced in separate publications by both Kuhn and Feyeraband as the rejection of the continuity and accumulative principle in science, given that the two "reject such characterizations of scientific progress because they recognize and emphasize that scientific revolutions result in changes in ontology. Such changes are not just refinements of, or additions to, the older ontology, such that these developments could be seen as cumulative additions to the already established theoretical views. Rather, the new ontology replaces its predecessor. Consequently, neither Kuhn nor Feyerabend can correctly be characterized as scientific realists who believe that science makes progress toward the truth." The last sentence of this quote subsumes a criticism of incommensurability that will be tackled a few lines later in this section. Both "paradigm shift" and "incommensurability" could be used in favour of the theory and development of "interdisciplinarity", particularly by postmodernists (Hutcheon, 1997). The various disciplines are, in many ways, "incommensurable" and the shift of paradigm might take place between the disciplines in the same way that it can occur within the same discipline. Indeed, viewing the same problem 
in the light of a continuous interplay between a host of "incommensurable" different disciplines (different world looks), could, paradoxically, lead to a deeper understanding of the problem, and a better academic tolerance among the scholars investigating the problem, as well. For incommensurability, be it "taxonomical incommensurability" (scientific theories and paradigms are largely determined by the semantics of the lexicon within the academic community of the discipline), or "methodological incommensurability" (the values along which lines these theories and paradigms are judged differ infinitely among theorists), in Kuhn's terms, is more likely to foster a framework of accepting the legitimacy of the differences both intra-disciplinary and interdisciplinary. A better way of capturing this, is Oberheim's, and Hoyningen-Huene's assertion (2012, p. 14) that "different scientists apply these values differently, and they may even pull in different directions, so that there may be rational disagreement between scientists from incommensurable paradigms, who support different theories due to their weighing the same values differently."

The theories of paradigm shift and incommensurability have, nonetheless, been interpreted differently by different scholars. They have probably proved to be "incommensurable" themselves, only to substantiate Oberheim, and Hoyningen-Huene's (2012, p. 3), claim that "Kuhn's notion of incommensurability in The Structure of Scientific Revolutions misleadingly appeared to imply that science was somehow irrational, and consequently, it faced many challenges and caused many confusions. "An example of this, underpins Hutcheon's (1997) staunch attack on postmodernists accusing them of failing to understand Kuhn, to the point of entirely "distorting" him. Despite being an interdisciplinarity vocal advocate himself, Hutcheon, accuses postmodernists of abandoning the principle of "authentic science" by misunderstanding Kuhn's theory. He maintains, all the way, that "interdisciplinarity necessarily means more than merely encouraging individual students and professors to select whatever they choose to study from an aggregate of unconnected opinions across a number of subject boundaries. Surely, it must involve the building of authentically scientific studies" (p. 4). Hutcheon's charge of distortion is steeped in his understanding that Kuhn's theory of paradigm applies only to "the common conceptual framework which has evolved for a specific problem area", and that this would mean a "universally accepted explanatory system" which guides the processes of both conducting and interpreting of research, whereas the postmodernists' understanding of Kuhn's paradigm is that it also involves "philosophical world views and to any and all of the equally untested competing 'models' in their field" (p. 7).

\section{Problems, Challenges, Drawbacks and Limitations of Interdisciplinarity}

Interdisciplinarity, though a liberating movement from the constraints of "disciplinarity", is however, given the current status quo of interdisciplinary research and practices, hampered by a variety of problems, challenges and threats. This section casts light on the actual and potential problems of interdisciplinarity.

Researchers working across disciplines may face the problem of being inherently-biased and ideologically-loaded by the theories, concepts, terminology preferred by their particular fields. Lele and Norgaard (2005) identify four barriers hindering research across boundaries; 1 . The existence of inherent value judgments which are characteristic of all scientific enquiry. This kind of bias manifests itself in the choice of research questions, variables, theoretical stance, research writing styles, etc. 2. The existence of an 'underlying assumption' when scholars from different disciplines attempt to deal with the same problem. These scholars, in many ways, tend to prefer certain models of understanding and explanation. 
3. The existence of 'epistemological differences ' between the various disciplines which may also entail 'built-in' theoretical and practical differences . 4. The existence of the influence of larger societal, cultural and economic forces outside academia which will result in certain choices and preferences in both disciplinary and interdisciplinary research. These forces are now at work, (e.g. the influences of increasing commoditization and commercialization of modern life exercised by big firms and huge international businesses) in both micro and macro levels. Additionally, working across a variety of disciplines may be blurred by a lack of field/disciplinary identity. Interdisciplinary work is innovative; and hence, having all the problems commonly associated with innovation and novelty.

In a more recent attach on interdisciplinarity, Jacobs (2013), argues that the benefits of interdisciplinarity have been over-estimated and that "disciplinarity" is inevitable, is still working and that blurring the boundaries between the disciplines have not really been a success. However, no matter how valid and strenuous these arguments leveled against interdisciplinarity, may at times look, there is evidently an increasingly growing need for rethinking disciplinarity, and seeing the wonder of what lies beyond one's own disciplinary boundaries (see the proceedings of a series of much more recent conferences such as the University College of London (UCL) June, 2014 and the Michigan State University Oct.2014 conference, and the "Petru Maior" University of Tîrgu Mureş, Oct. 2014 8th International Conference on Interdisciplinarity in Engineering).

\section{The Need for Interdisciplinarity in the Nascent Saudi Universities}

The Arab world, in general, is lagging behind the world, with respect to the incorporation of interdisciplinary studies. A glimpse at the universities of the Arab world, will be sufficient to unveil the appalling gap, regarding the necessity of interdisciplinarity not only as a research perspective, but also with regard to the introduction of interdisciplinary studies at the undergraduate/postgraduate levels. Though the first international conference on interdisciplinary studies was held in Paris in 1972, it is hard to tell if any such conference has ever been held in the Arab world, despite the rare and sporadic writings and conventions about interdisciplinary studies, by only a handful of Arab scholars. Three examples of these sporadic instances, are the conference on 'Arabic Language and Interdisciplinary Studies' held in Cairo, Dar al-U'lum, 4/3/2007, and the establishment of the 'Interdisciplinary Centre for Arabic Language', at Imam Muhammad Ibn Saudi Islamic University and a centre for interdisciplinary research and studies in Halwan University. These examples, innovative as they might obviously be, are self-evidently quite limited in perspective and domain. What is more, they either operate within a disciplinary framework, such as Arabic language, or focus primarily on coordinating policies and research as the one in Halwan did (the latter centre is a real breakthrough, for that matter).

\section{Interdisciplinarity and the Labour Market}

As economic conditions are swiftly changing worldwide, and job markets are getting more and more tough and highly competitive in the Gulf and Saudi Arabia, nascent universities should seek ways to improve their graduates' skills, knowledge and competences, in order to be able to compete well, within a sweepingly changing world economy. Traditional" disciplinarity" has been shown, in many ways, to produce new graduates with many professional weaknesses, limitations and inadequacies, rendering them largely inept to cope with the hugely demanding new job market. In an increasingly globalised and cyberised age, most jobs are progressively requiring a network of interdependent skills and a range of 
competences that only interdisciplinarity and interdisciplinary studies/sciences can more adequately provide. The new interdependent skills, which the present "disciplinary education" clearly and sadly lacks, are particularly required in private companies and firms, and there is currently a growing dissatisfaction of the performance of employees and new graduates(cf. www.altadreeb.net), with regard to these skills.

Quite relevantly, a number of Saudi studies have uncovered the huge gaps between the skills and knowledge required by government and private employers alike, and the reality of the skills of the university graduates. An example of this, is revealed by a doctorate thesis conducted by al-Zahrani (2010). Zahrani's thesis has notably confirmed the employers' growing dissatisfaction with the graduates/employees' lack of communicative English skills, critical skills and the ability to work independently in increasingly pressing labour environments.

\section{Method}

\subsection{Data from Majma'ah University}

Given the plenty merits and functions of interdisciplinarity discussed in this study, it is imperative that the Saudi universities, and, above all, the nascent ones such as Majmaah University, introduce interdisciplinarity and interdisciplinary studies in their research, teaching and training programmes. With these questions and issues in mind, a set of various data were collected from one of the leading newlyestablished Saudi universities (Majma'ah university), to explore some of its leading administrators' and academics' opinions of the possibility of introducing/adopting interdisciplinarity in the university. The data was predominantly qualitative consisting of focus discussions and interviews conducted across the university. The following section demonstrates and reports the results of these discussions and interviews.

\section{Qualitative Data: Focus Discussions and Interviews}

\subsection{Focus Discussions}

Various "focus-discussions" were held to discuss the issue of interdisciplinarity and the importance of introducing it in the Arab academia, in general, and the newly-established Saudi universities (the case of Majmaah university), in particular. The subjects who took part in these focus discussions were highly qualified and trained academics working in Majmaah university. The issue was probed from various perspectives: research, administrative, cultural, labour market, etc. Most of the participants agreed on the significance of adopting interdisciplinary perspectives in research. They largely believed that modern research can benefit considerably from adopting an interdisciplinary perspective. They, furthermore, tended to be supportive of interdisciplinarity in administration. However, most of them observed that the long tradition of Arabic academia which favoured disciplinarity would constitute a real obstacle resisting the adoption of interdisciplinarity. As the discussion intensified and got more focused, it became apparent that most of the discussants became aware of the importance of interdisciplinarity as a new paradigm in Arabic academia.

\subsection{Interviews}

A group of around (10) top administrators in Majma'ah university (department heads, vice-deans, college deans, deputy vice-chancellors, etc.), were interviewed to probe their opinions and attitudes about 
introducing interdisciplinarity in the university. A few leading academics in the university, were also interviewed. Some of the interviews were completed in more than one session. The method of the interviews varied from semi-structured to open-ended and the questions revolved around: The extent to which the interviewees see the importance of interdisciplinarity; the possibility of introducing interdisciplinarity in Majma'ah university (by e.g. establishing interdisciplinary administrative bodies such as units at department and college levels, such as, an agency and deanship at the university level); the significance of interdisciplinarity in research coupled with the impact of interdisciplinarity on the labour market.

Results of the interviews generally confirmed the results of the focus group discussions. Most of the top administrators of the university saw the validity and importance of bridging the present gaps between academic disciplines encouraging the tendency towards establishing administrative bodies for that purpose. However, they seemed to disagree as to the best ways of realizing the purposes of connecting the disciplines within the university. Whilst some of them favoured establishing an administrative body at the university (e.g. deanship), some others including a leading administrator favoured the tendency of starting first at the department and college levels by establishing small "interdisciplinary units". With regard to the significance of introducing interdisciplinarity in research, the informants/interviewees agreed almost unanimously for the existence of an apparent need for this. Despite this, it was, all the same, clear that some of the interviewees preferred adopting interdisciplinarity at the levels either of the same umbrella discipline (intra-disciplinarity) or between a set of more related disciplines. Most of the worries about interdisciplinarity such as losing "my discipline identity" that were discussed in the literature were also reiterated here in these interviews. Indeed, some of the reservations on the part of the interviewees, particularly, the academics, expressed the usual drawbacks and limitations of interdisciplinarity discussed earlier in this study (see section 5).

Asked whether they thought interdisciplinarity would make the graduates of the new universities more competitive in the new labour market, around 50\% of the informants agreed (both top administrators and academics), $30 \%$ were unsure about the labour market conditions and 20\% disagreed that interdiscipliarity would increase the competitiveness of the university graduates. Faced with the new facts of the labour market which is increasingly demanding graduates having "interdependent skills", 70\% of the academics (from various specialty backgrounds) interviewed, thought that an interdisciplinary approach is likely to provide graduates with most of these skills. In fact, some of them were already apparently dissatisfied with their graduates' skills and the degree of their competitiveness in the market. "I am actually not sure if my students will be able to compete even in the traditional spheres of labour market", commented one brilliant and senior academic. Another academic was so enthusiastic about the introduction of interdisciplinarity, that he believed that his discipline itself was, in reality, a product of interdisciplinarity, "My current field itself would not have been possible, had it not been for the works of various other disciplines", said he (his area is "special education"). Medical and engineering academics were also very favourable of interdisciplinarity. This can be viewed as plainly a result of their awareness of the real gaps and limitations of their subdisciplines even within their single discipline (despite the many merits of this, of course). There were educators among the interviewees who did not only display quite positive attitudes towards interdisciplinarity, but also further gave a special insight into the issue. 
Thus, it would be reasonable to argue that the mixed-method data collected (observational data, focus discussions, interviews) provide strong evidence that interdisciplinarity (as an educational and research philosophy) and interdisciplinary studies are hugely needed to be incorporated into the universities of the Arab world, generally, and the nascent Saudi universities, in more specific terms. The two hypotheses in (1.2) have been largely confirmed by the mixed data provided from Majmaah university, as an example of a newly-established university that could benefit tremendously from the adoption of interdisciplinary studies and interdisciplinarity (see also the questions in 1.1).

\section{Summary, Conclusion and Implications}

This study discusses the issue of "interdisciplinarity" and "interdisciplinary studies" and the need for this kind of studies, in Arabic academia, in general terms, and the nascent Saudi universities and colleges, in more specific terms. Drawing on the growing literature of "interdisciplinarity", the study disports the multiple drawbacks, weaknesses and limitations of "disciplinarity" that have stamped modern education since the late nineteenth century, and consequently have triggered the rising need for filling the gaps, via the introduction of interdisciplinarity and interdisciplinary studies. That said, the variable conceptual, theoretical and practical problems are also probed, and the potential and actual challenges are laid bare. In addition, the interrelationships between the term "interdisciplinarity" and the set of other related terms: intra-disciplinarity, cross-disciplinarity, multi-disciplinarity, pluri-disciplinarity, trans-disciplinarity and post disciplinarity, are exhibited and discussed.

Most importantly, the study unveils the urgent need to incorporate interdisciplinarity and interdisciplinary studies into the nascent Saudi universities and colleges, with Majm'ah University taken as a case. It is shown that these universities, and in particular Majm'ah University, can considerably benefit from the adoption of these studies. Taking into account, that many studies have disclosed the big gap between the highly demanding and challenging new labour market requirements, and the status quo of the Saudi university graduates, the study concludes that interdisciplinarity/interdisciplinary studies will probably develop the students' critical and interdependent skills needed by today's market. Accordingly, this is likely to increase the competitiveness of Majma'ah graduates and that of the rest of other new universities/colleges in Saudi Arabia; hence contributing considerably to building the new knowledge economy and knowledge community which is a major and repeatedly stated aim of Saudi education authorities. Within a growingly competitive educational and labour environment and work market conditions, interdisciplinary studies/interdisciplinarity could markedly help the nascent universities form their own self-branding and can therein, constitute their own unique academic and research character.

The study utilizes a set of qualitative data collected from Majma'ah university academic staff members and top administrators to investigate the possibility and benefits of introducing interdisciplinarity in the university. Focus discussions and interviews were conducted across the university over a period of several months. The results of these discussions and interviews were analysed and discussed drawing on qualitative methods pertinent for highlighting the type of these questions. Results of the interviews and discussions after coding and using thematic analysis, largely confirmed the general need for adopting interdisciplinarity in Majma'ah university. It is shown that the introduction of interdisciplinarity and interdisciplinary studies could actually materialize in a totally new paradigm in the university. 
Further studies on interdisciplinarity and interdisciplinary studies are needed across Saudi Arabia and the Arab world. Indeed, particular conferences and workshops are recommended to be held on interdisciplinarity and interdisciplinary studies in Saudi Arabia and the Arab world. Though studies of this kind are usually of exploratory nature, quantative methods and mixed-method studies can also be used. Being more inclined to setting new horizons and paradigms in education, nascent universities and colleges (both governmental and private) can take the initiative in this respect.

\section{References}

Al-Zahrani, A. (2010). The Lack of Compatibility between the Requirements of the Saudi Labour Market and the Saudi Higher Education Outcomes: Reality, Causes and Solutions. unpublished $\mathrm{PhD}$ thesis, Um al-Qura university, KSA.

Ausburg, T. (2006). Becoming interdisciplinary: An introduction to interdisciplinary studies. USA: Kendall Hunt.

Axinn, W., \& Pearce, L. (2007). Mixed methods data collection strategies ( $2^{\text {nd }}$ edn.). New York: Cambridge University Press.

Dale, A. (2008). Crossing Disciplinary Boundaries. In: NCRM Research Methods Festival 2008, 30th June - 3rd July 2008, St Catherine's College, Oxford. (Unpublished).

Derrida, J. (1973). Speech and Phenomena and Other Essays on Husserl's Theory of Signs, trans. By Allison, David, Evanston: Northwestern University Press.

Derrida, J. (1976). Of Grammatology, trans. by, G., Baltimore \& London: Johns Hopkins University Press

Derrida, J. (1978). Writing and difference, trans. Bass, A. Chicago: University of Chicago Press.

Ethan, K. (2008). Interdisciplinary Studies at the Crossroads. Liberal Education, 94 (1), 6-11.

Fairclough, N. (1989). Language and power. London: Longman.

Feyerabend, P. (1962). Explanation, Reduction and Empiricism, in H. Feigl and G. Maxwell (ed.), Scientific explanation, space, and time, (Minnesota Studies in the Philosophy of Science, Volume III), Minneapolis: University of Minneapolis Press (pp. 28-97).

Foucault, M. (1995). Discipline \& punish: The birth of the prison. trans. By Sheridan, Alan., Vintage Books , (1 ${ }^{\text {st }}$ edn. 1975).

Foucault, M. (2002). Archaeology of knowledge: The discourse of language. trans. By Smith Sheridan. London: Routledge ( $1^{\text {st }}$. edn. 1969).

Foucault, M. (2006). History of madness. trans. By Murphy, J. London: Routledge ( ${ }^{\text {st }}$ edn. 1961).

Heidegger, M. (1996). Being and Time (trans. By Stambaugh, J. Albany: State University of New York University Press. (first trans. By Macquarie, J. and Robinson, E. 1962).

Hutcheon, D. (1997). An Interdisciplinary Approach to Social Science Research. A paper presented at the Conference on Interdisciplinary Studies at the University of British Columbia, Canada.

Hutcheon, L. (2004). A poetics of postmodernism: history, theory, fiction. padstow, $\left(11^{\text {th }} \mathrm{edn}.\right)$. Cornwall: TJ International Ltd.

Jacobs, J. (2013). In defense of disciplines: Interdisciplinarity and specialization in the research university. Chicago: University of Chicago Press.

Jensenius, R. (2012). Disciplinarities: intra, cross, multi, inter, trans, http://www.arj.no, retrieved on 12 March.

Klein, T. J. (1990). Interdisciplinarity: History, theory and practice. Detroit: Wayne State University Press.

Klein. T. J. (1990). Interdisciplinary Resources: A Bibliographical Reflection. Issues in Integrative Studies, 8, 35- 67.

Klein, T. J. (2002). Mapping interdisciplinarity studies. Washington D.C.: Association of American Colleges and Universities. 
Klein, T. J. (2005). Humanities, culture and interdisciplinarity: The changing American academy. Albany: State university of New York Press.

Klein, T. J. (2010). Creating interdisciplinary campus cultures. Sanfrancisco: Jossy Bass and the Association of American Colleges and Universities.

Kuhn, T. (1962). The structure of scientific revolutions. Chicago: University of Chicago Press.

Lattuca, L. (2001). Creating interdisciplinarity: Interdisciplinary research and teaching among college and university faculty. USA: Vanderbilt University Press.

Lele, S., \& Norgaard, R. (2005). Practicing interdisciplinarity. BioScience, 55 (11), 967.

Lipton, M. (1970). Interdisciplinarity studies in less developed countries. Journal of Development Studies, 7 (1), 5-18.

Lise, M. (2004). The Cartesian Distinction between Thinking Things and Objects makes no Sense"(unpublished).

Moran, J. (2010). Interdisciplinarity. London: Taylor and Francis ( $2^{\text {nd }}$ edn.).

Nicolescu, B. (2002). Manifesto of transdisciplinarity (trans. By Voss, Karen-Claire). USA: SUNY Press/Albany: State University of New York Press.

Nicolescu, B. (n.d.). Transdisciplinarity: Past, Present and Future. www.movingworldviews.net/Downloads/Papers/Nicolescu.pdf

Oberheim, E., \& Hoyningen-Huene, P. (2012). The Incommensurability of Scientific Theories, The Stanford Encyclopedia of Philosophy (Summer 2012 Edition), Edward N. Zalta (ed.), URL <http://plato.stanford.edu/archives/sum2012/entries/incommensurability/>.

http://www.units.miamioh.edu/aisorg /Association for Interdisciplinary Studies, Michigan university, 36th Annual AIS Conference, Oct. 15-19, 2014.

http://www.inter-eng.upm.ro/2014, The International $8^{\text {th }}$ Conference on Interdisciplinarity in Engineering, Oct. 2014 Romania./ 